\title{
A theoretical explanation of the effect of oxygen poisoning on industrial Haber-Bosch catalysts
}

Rohr, Brian A.; Singh, Aayush R.; Nørskov, Jens K.

Published in:

Journal of Catalysis

Link to article, DOI:

10.1016/j.jcat.2019.01.042

Publication date:

2019

Document Version

Peer reviewed version

Link back to DTU Orbit

Citation (APA):

Rohr, B. A., Singh, A. R., \& Nørskov, J. K. (2019). A theoretical explanation of the effect of oxygen poisoning on industrial Haber-Bosch catalysts. Journal of Catalysis, 372, 33-38. https://doi.org/10.1016/j.jcat.2019.01.042

\section{General rights}

Copyright and moral rights for the publications made accessible in the public portal are retained by the authors and/or other copyright owners and it is a condition of accessing publications that users recognise and abide by the legal requirements associated with these rights.

- Users may download and print one copy of any publication from the public portal for the purpose of private study or research.

- You may not further distribute the material or use it for any profit-making activity or commercial gain

- You may freely distribute the URL identifying the publication in the public portal 


\title{
A theoretical explanation of the effect of oxygen poisoning on industrial Haber-Bosch catalysts
}

\author{
Brian A. Rohr ${ }^{a}$, Aayush R. Singh ${ }^{a}$, Jens K. Nørskov ${ }^{a, b, c, *}$ \\ a SUNCAT Center for Interface Science and Catalysis, Department of Chemical Engineering, Stanford University, Stanford, CA 94305, USA \\ ${ }^{\mathrm{b}}$ SUNCAT Center for Interface Science and Catalysis, SLAC National Accelerator Laboratory, Menlo Park, CA 94025, USA \\ ${ }^{\mathrm{c}}$ Department of Physics, Technical University of Denmark, DK-2800 Kgs. Lyngby, Denmark
}

A R T I C L E I N F O

Keywords:

Ammonia

Haber-Bosch

Alkali promotion

Kinetic modeling

Catalyst poisoning

Density functional theory

\begin{abstract}
A B S T R A C T
The Haber-Bosch process has been studied extensively, yet a low-temperature, low-pressure process remains elusive. As has been shown many times, this stems in part from the difficulty of breaking the $\mathrm{N}-\mathrm{N}$ triple bond. In this work, we highlight an additional reason for the lack of a low-temperature ammonia synthesis process: the effect of oxygen poisoning at low temperature. Using density functional theory (DFT), we have created a new model for the active site of industrial Haber-Bosch catalysts which explicitly includes the potassium promoter. Furthermore, we present a new micro-kinetic model for ammonia synthesis that includes the effect of oxygen poisoning due to trace water content in the input gas stream. Our model agrees well with previous experiments and shows that devising a strategy to avoid oxygen poisoning is crucial to creating a low-temperature Haber-Bosch process. Additionally, the model suggests that using a weaker-binding catalyst is one way to avoid oxygen poisoning if it is impractical to remove all water from the reactor.
\end{abstract}

\section{Introduction}

The Haber Bosch process is run at high temperature and high pressure $[1,2]$. The high temperature is required to avoid the poisoning of the surface with surface-bound reaction intermediates, and the high pressure is required to drive the overall process forward at these elevated temperatures. Ammonia (or urea) is produced at a small number of large facilities, and the product is transported to the farms where it is used as fertilizer [3]. A decentralized ammonia production system, one with a large number of small reactors distributed throughout areas with farmland, would be advantageous because it would reduce distribution costs and it could be integrated with sustainably produced hydrogen based on solar or wind electricity. In order to decentralize production, a lower pressure and therefore lower temperature process would be highly desirable since it would significantly lower equipment cost and safety concerns [4].

One reason that a low temperature Haber Bosch process has not been attained is that, on industrial catalysts, as temperature is lowered below the industrial conditions $(700 \mathrm{~K}, 100 \mathrm{bar})$, the rate of reaction falls even faster than the Arrhenius equation would predict, and this effect is more pronounced when more water vapor

\footnotetext{
* Corresponding author.

E-mail address: jkno@dtu.dk (J.K. Nørskov).
}

is present [5]. This suggests that the active sites of industrial catalysts are poisoned by oxygen or hydroxyl groups at low temperatures. Therefore, as researchers continue to work toward creating catalysts that enable a low temperature Haber-Bosch process, it is important to have a good theoretical understanding of the effect of oxygen poisoning on industrial catalysts. The theoretical model presented in this work is in agreement with existing experiments, and it provides new insight into the nature of the active site, the effect of K-promotion, and how the presence of water affects a wide variety of catalysts.

\section{Computational methods}

Chemisorption energies of $\mathrm{N}, \mathrm{NH}, \mathrm{NH}_{2}, \mathrm{NH}_{3}, \mathrm{O}$, and $\mathrm{OH}$ on several surfaces were calculated using the ASE-Espresso [6] implementation of density functional theory using the BEEF-VdW exchange correlation functional [7]. For all gas phase calculations, a single gamma point was used with a plane wave cutoff of $600 \mathrm{eV}$ and a density wave cutoff of $6000 \mathrm{eV}$. For all surface calculations, a $4 \times 4 \times 1$ Monkhorst-Pack k-point grid [8] was used with a plane wave cutoff energy of $600 \mathrm{eV}$ and density wave cutoff energy of $6000 \mathrm{eV}$. For bulk calculations, an $11 \times 11 \times 11 \mathrm{k}$-point grid was used with a $800 \mathrm{eV}$ plane wave cutoff and an $8000 \mathrm{eV}$ density wave cutoff. A lattice constant optimization was performed on FCC bulk 
structures of rhenium, ruthenium, iron, rhodium, and platinum. The resulting relaxed structures were cut into 211 stepped surfaces using the Atomic Simulation Environment's built-in surface cutting method. The surface was four layers deep with the bottom two layers fixed, and the surface was two atoms by three atoms. $20 \AA$ of vacuum separated the slabs in the $z$-direction, and the ASE builtin dipole correction was applied. A convergence test showed that the $\mathrm{N}$ and $\mathrm{O}$ chemisorption energies did not change substantially using five or six layers of metal, so four layers were used for all further calculations. Another convergence test showed that doubling the unit cell width to three atoms by four atoms had no substantial effect on the $\mathrm{N}$ and $\mathrm{O}$ binding energies, regardless of whether $\mathrm{N}, \mathrm{O}$, or a vacancy was in the neighboring active site. To determine the structure of the catalyst with a potassium promoter, a geometric relaxation was performed on several different configurations of potassium and oxygen, and the most stable one was chosen. Using geometric relaxations, the chemisorption energy of $\mathrm{N}, \mathrm{NH}, \mathrm{NH}_{2}$, $\mathrm{NH}_{3}, \mathrm{O}$, and $\mathrm{OH}$ were calculated in the oxygen vacancy site of the five FCC K-promoted catalysts, shown in Fig. 1. The gas phase reference states were $\frac{1}{2} \mathrm{~N}_{2}(\mathrm{~g})$ for $\mathrm{N}, \frac{1}{2} \mathrm{H}_{2}(\mathrm{~g})$ for $\mathrm{H}$, and $\mathrm{H}_{2} \mathrm{O}(\mathrm{g})-\mathrm{H}_{2}(\mathrm{~g})$ for $\mathrm{O}$. BCC Iron and HCP Ruthenium are more computationally expensive to work with because BCC iron requires the use of spin polarization and the 0001 step requires a larger unit cell, but these materials are also important Haber-Bosch catalysts. The ${ }^{*} \mathrm{NH}_{x}$ and oxygen chemisorption energies were calculated on BCC iron, and the nitrogen and oxygen binding energies were calculated on HCP Ru. The stepped Iron BCC unit cell was the 210 step, a step in the BCC-100 facet with terraces the same size as the FCC-211 step. The unit cell used also had four layers, three by two surface atoms, and $20 \AA$ of vacuum. The calculation parameters used were the same as those used for the FCC-211 surface calculations except spin polarization was turned on. The stepped Ruthenium HCP unit cell used also had four layers with the bottom two fixed and $20 \AA$ of vacuum. Due to the nature of the HCP structure, there are two different kinds of steps with 0001 terraces. Therefore, the unit cell had six by two surface atoms and included two steps per unit cell. The built-in ASE surface cutting method was used with indices 105 to generate the surface. The k-point grid was modified to $2 \times 4 \times 1$ to keep k-point density constant across the study, and all other calculation parameters were the same as the ones used in the FCC-211 surface calculations. Each step is a distinct type of active site. The oxygen and nitrogen chemisorption energies at each step were calculated, and the energies corresponding to the more active site were chosen because that site is the relevant one for the Haber-Bosch process. The zero point energy and entropy of each surface-bound intermediate was calculated on each K-promoted FCC catalyst using ASE's built-in harmonic thermodynamics package and the same calculation parameters as those used for the surface calculations. The zero point energy and entropy of each intermediate was found to be very similar on the five catalysts. The zero point energy and entropy from the $\mathrm{K}$-promoted rhodium catalyst were used in the microkinetic model because this catalyst has moderate reactivity; it is not an extreme case.

The barriers were calculated using the fixed bond length (FBL) method. This method has been shown to produce reliable transition state energies at a lower cost than the nudged elastic band method [9-11]. The DFT calculation parameters used were the same as those used for the surface calculations. The N-N transition state was found by placing two adsorbed nitrogen atoms in the unit cell, one at the upper step, and one at the lower step, performing a geometric relaxation, and applying the FBL method to the relaxed structure. The $\mathrm{N}-\mathrm{H}$ transition state energy was found in a similar manner. An adsorbed $\mathrm{H}$ atom was added to the upper step, and separately, to the lower step, of the unit cell with adsorbed nitrogen in the active site. A geometric relaxation was performed on each, and the more stable configuration was chosen. This unit cell with ${ }^{*} \mathrm{~N}$ in the active site and $\mathrm{H}^{*}$ on the nearby terrace was used to calculate the $\mathrm{H}^{*}$ chemisorption energy using $\frac{1}{2} \mathrm{H}_{2}(\mathrm{~g})$ and the relaxed unit cell with only ${ }^{*} \mathrm{~N}$ in the active site as the reference states. We believe this to be the physically relevant quantity because, in the kinetic model used in this study, the ${ }^{*} \mathrm{NH}_{\mathrm{x}}$ intermediates in the active site at the step react with adsorbed hydrogen atoms on the nearby terrace. The FBL method was then applied to the ${ }^{*} \mathrm{~N}+{ }^{*} \mathrm{H}$ unit cell to find the transition state energy. The remaining hydrogenation barriers, $\mathrm{NH}-\mathrm{H}$ and $\mathrm{NH}_{2}-\mathrm{H}$ were found in the same way, but starting with the unit cells with the active site occupied by $\mathrm{NH}$ and $\mathrm{NH}_{2}$, respectively. The zero point energy and entropy of each transition state was determined using the harmonic oscillator approximation implemented in ASE-Espresso. Each transition state has an imaginary vibrational mode, which is an expected characteristic of a transition state structure. When calculating the entropy of each transition state, the imaginary modes were handled using the method proposed by Brogaard et al. [12] All calculated adsorption energies, entropies, zero point energies, and vibrational modes are tabulated in the supplemental information.

\section{Results and discussion}

\section{1. $\mathrm{K}-\mathrm{O}$ structure}

In order to create an accurate microkinetic model, the surface must be understood. The industrial Haber Bosch catalyst is known to be a potassium and oxygen-containing promoter on stepped
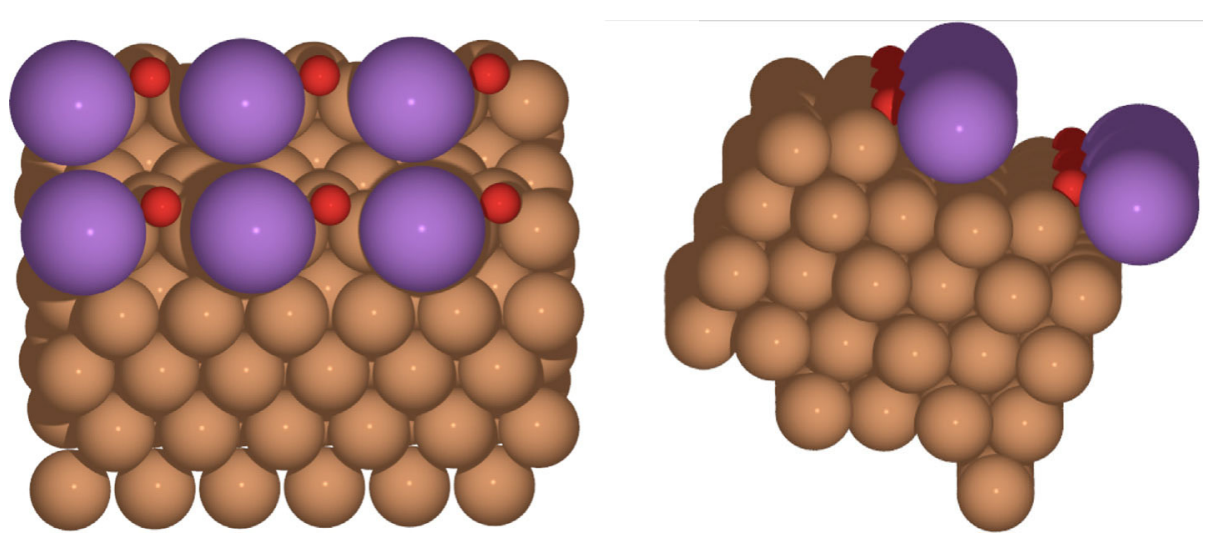

Fig. 1. Catalyst structure. 
iron [13]. The stability of several different K-O structures were calculated using DFT. The most stable configuration of potassium oxide on the stepped iron surface was found to be an alternating $\mathrm{K}-\mathrm{O}$ motif along the step edge, shown in Fig. 1. The step sites of metal surfaces have previously been shown to be more reactive than the terraces, so this result is unsurprising. On iron, this most stable $\mathrm{K}-\mathrm{O}$ structure has a calculated formation energy of $-1.71 \mathrm{eV}$ relative to the following reference states $\mathrm{Fe}$ : the bare stepped iron surface, $\mathrm{K}$ : bulk potassium oxide, and $\mathrm{O}: \mathrm{H}_{2} \mathrm{O}(\mathrm{g})-\mathrm{H}_{2}(\mathrm{~g})$. Even under the strong reducing conditions of the Haber-Bosch process ( $800 \mathrm{~K}$ and $150 \mathrm{bar}$ ), the decomposition reaction to form water and bulk potassium oxide is thermodynamically disfavored by $0.96 \mathrm{eV}$, assuming $1 \mathrm{ppm}$ water and $75 \% \mathrm{H}_{2}(\mathrm{~g})$. Therefore, it is unfavorable for this structure to decompose into bulk potassium oxide and water vapor, even under reaction conditions. This is in agreement with previous experiments, which show that there are metal-oxygen bonds in the industrial catalyst, that the presence of oxygen increases the stability of the promoter, and that the promoter remains stable at high temperature [13]. The positions of the atoms and bader charges on each atom are available in Table 12 in the supplemental information [14].

\subsection{Scaling relations}

It has previously been shown for many classes of systems that the adsorption energies of reaction intermediates are roughly linearly related to each other for a given class of materials [15]. These linear scaling relations for the nitrogen reduction intermediates have already been developed for stepped metal surfaces [16]. In this study, similar linear scaling relations, shown in Fig. 2, were developed for all of the nitrogen reduction intermediates in the oxygen vacancy site in the $\mathrm{K}-\mathrm{O}$ motif described in the previous section. It was found that the nitrogen binding energy in this vacancy site was unchanged regardless of whether the neighboring site was empty, contained an $\mathrm{O}$, or contained an $\mathrm{N}$. This is because each active site is isolated from its neighboring active site by a potassium atom. Therefore, adsorbate-adsorbate interactions were neglected in this study, and we suggest that this helps to explain why previous theoretical kinetic models were able to match experiment closely without taking adsorbate-adsorbate interactions into account.

All of the K-promoted lines follow a similar slope to their plain stepped metal counterparts. This indicates that each adsorbate
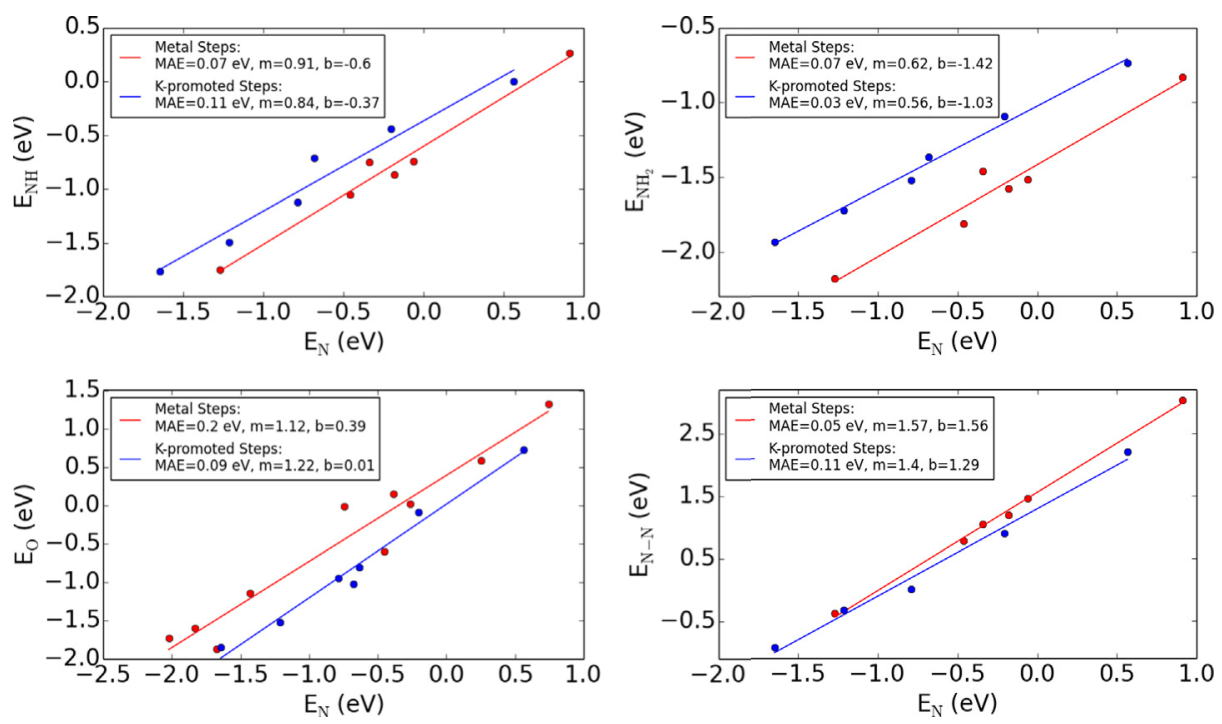

makes approximately the same number of bonds to the surface in each case. Furthermore, this indicates that the potassium promoter does not influence the binding energies of the intermediates through bonding directly with the adsorbates. The intercepts of several of the lines, however, are affected. Therefore, despite not forming bonds directly to the adsorbates, the potassium in $\mathrm{K}$ promoted catalysts does influence the energetics of the surfacebound intermediates. We attribute this to dipole-dipole interactions.

There are three important vertical shifts in the scaling lines. First, the $\mathrm{N}-\mathrm{N}$ transition state energy versus $\mathrm{N}$ binding energy scaling line is about $0.19 \mathrm{eV}$ lower in the $\mathrm{K}$-promoted case than the pure metal case (at a ${ }^{*} \mathrm{~N}$ binding energy of $-0.5 \mathrm{eV}$ ). This means that for a catalyst with any given nitrogen binding energy, the Kpromoted form of the catalyst will have a lower $\mathrm{N}-\mathrm{N}$ transition state energy than the pure metal step edge. This can be explained through dipole-dipole interactions, demonstrated in Fig. 3. It has previously been shown that the N-N bond is broken through addition of electrons to antibonding states, giving a partially negatively charged transition state [17]. In the K-promoted case, this transition state is stabilized by the electropositive potassium on the surface, immediately next to the $\mathrm{N}-\mathrm{N}$ transition state on the step edge. This explanation for the stabilization of the N-N transition state has been presented previously, [5] so the downward shift in the scaling line observed here is in agreement with previous work.

The second important shift is in the ${ }^{*} \mathrm{NH}_{2}$ line. This late intermediate in the nitrogen reduction pathway is less stable on the $\mathrm{K}$ promoted catalysts by about $0.4 \mathrm{eV}$ on the most active catalysts. We attribute this effect to steric hindrance as well as a dipole effect, shown in Fig. 4. The partial positive charge on the $\mathrm{H}$ atoms in ${ }^{*} \mathrm{NH}_{2}$ are slightly destabilized by the presence of the neighboring electropositive potassium atom. Similarly, K-promotion causes an upward shift in the ${ }^{*} \mathrm{NH}$ vs ${ }^{*} \mathrm{~N}$ scaling line by about $0.2 \mathrm{eV}$. Again, we attribute this effect to steric hindrance and dipole-dipole interactions, but the magnitude of each effect is less than the ${ }^{*} \mathrm{NH}_{2}$ case simply because ${ }^{*} \mathrm{NH}$ is less bulky and less polar. Since ${ }^{*} \mathrm{NH}_{2}$ and ${ }^{*} \mathrm{NH}$ are the surface species that dominate the coverage of active sites on the pure metal steps under industrial conditions, destabilizing these species increases the rate of reaction. We suggest that the increased activity of $\mathrm{K}$-promoted catalysts is primarily due to these two effects.

A third important shift in scaling is the ${ }^{*} \mathrm{O}$ vs ${ }^{*} \mathrm{~N}$ line. Surfacebound oxygen is stabilized by the presence of the potassium.

Fig. 2. Linear scaling relations: a plot of the electronic binding energy of each intermediate as a function of the nitrogen electronic binding energy. Data for the binding energies of the nitrogen intermediates on the pure metal steps are taken from Medord et al. [16]. 


\section{K Promoter}

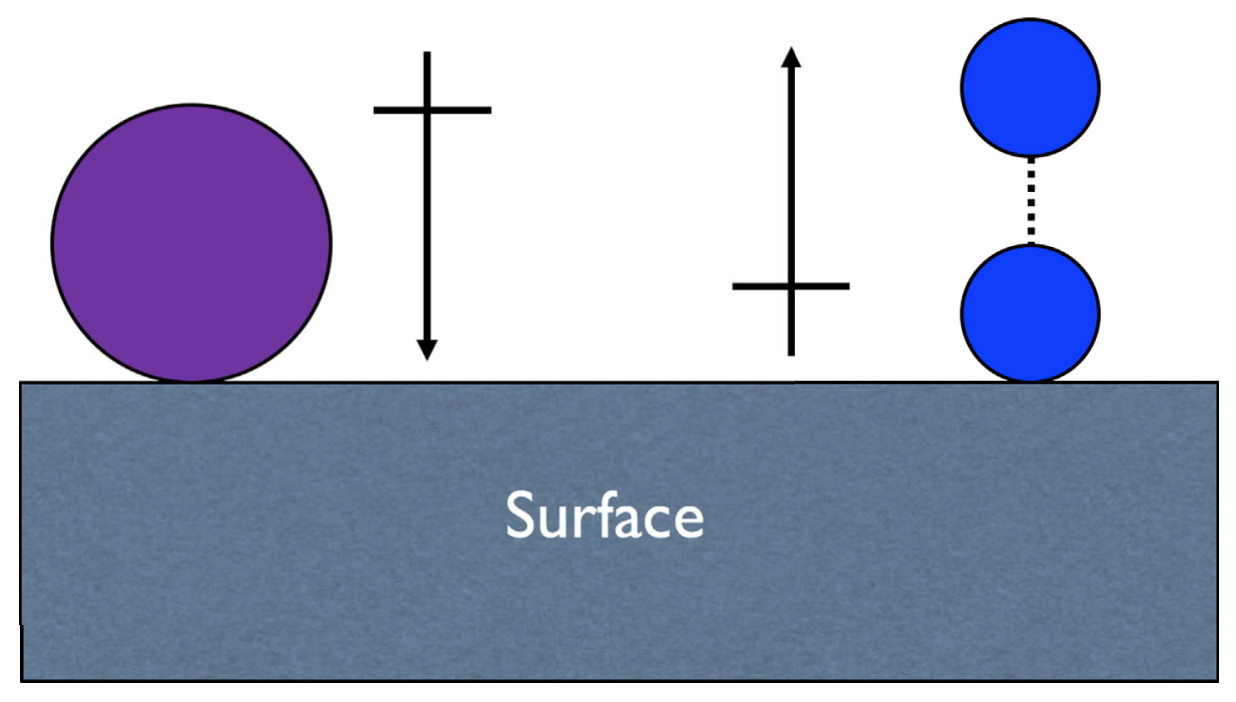

Fig. 3. Graphical demonstration of the stabilizing effect of the K-promoter on the *N-N transition state.

*N-N Transition

State
$* \mathrm{NH},{ }^{*} \mathrm{NH} 2$

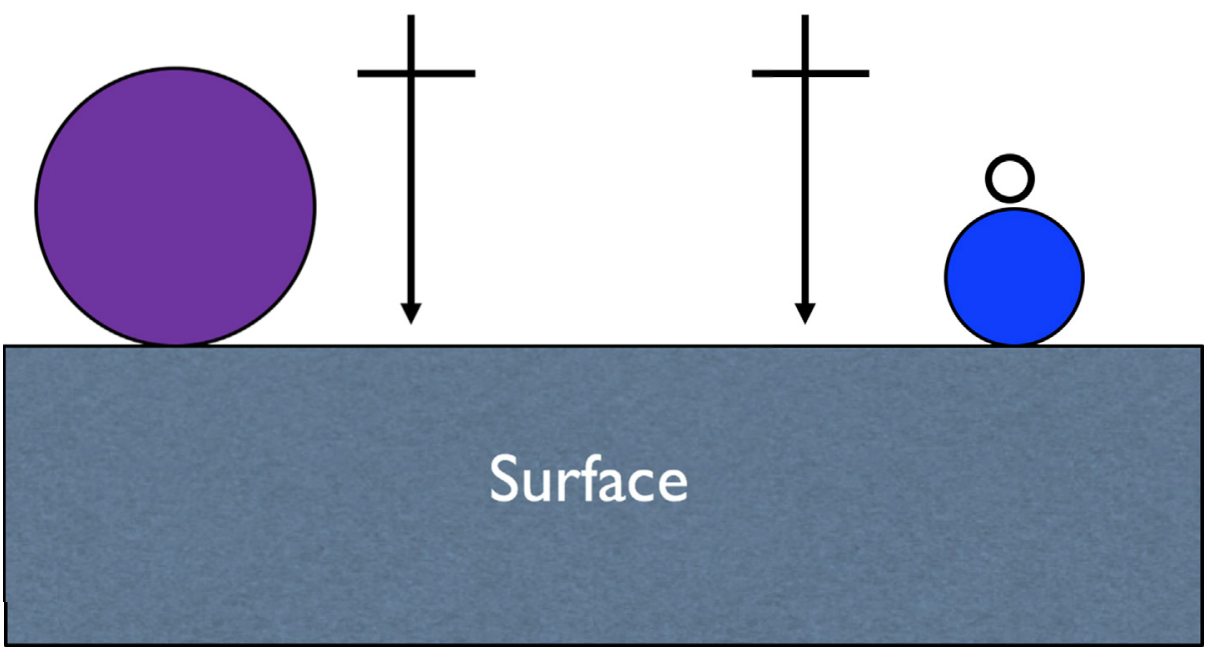

\section{Surface}

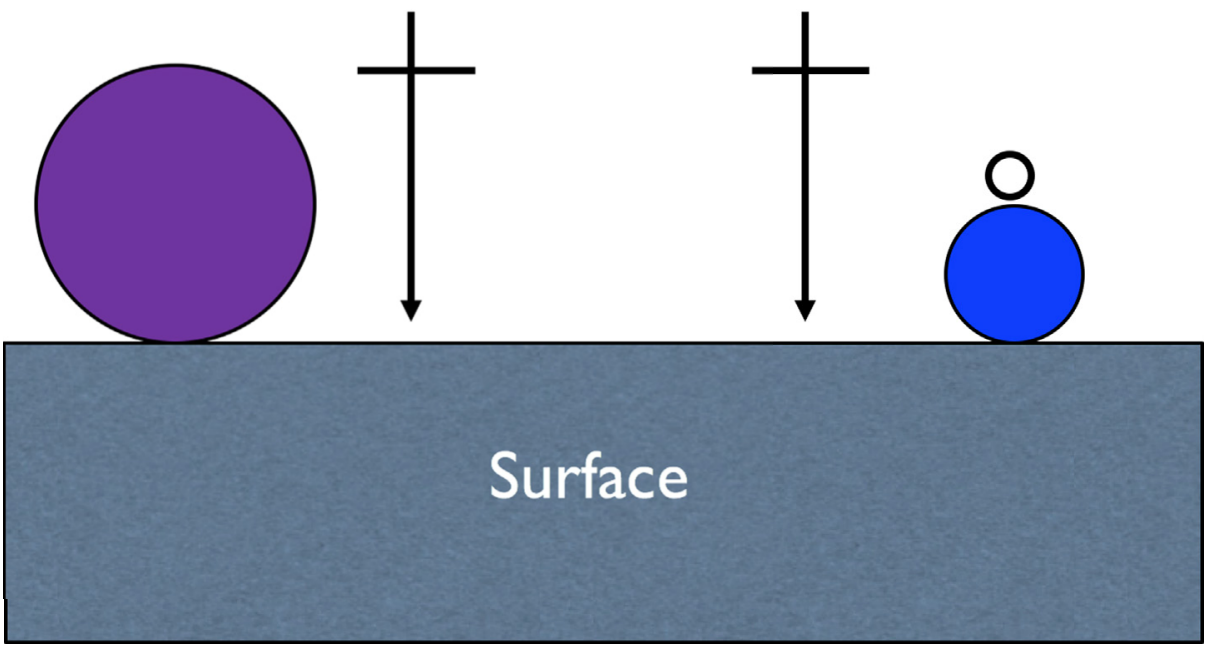

Fig. 4. Graphical demonstration of the destabilizing effect of the K-promoter on the ${ }^{*} \mathrm{NH}$ and ${ }^{*} \mathrm{NH}_{2}$ intermediates.

Therefore, while these catalysts are much more active, they are also more susceptible to oxygen poisoning. This is also in agreement with experiments [18]. Furthermore, according to the calculations in this study, potassium promoted iron falls slightly below the ${ }^{*} \mathrm{O}$ vs * $\mathrm{N}$ scaling line, showing that iron is particularly oxophilic even compared to the other potassium promoted metal steps.

\subsection{Microkinetic model}

A steady state kinetic model was solved using the scaling relations presented in the previous section, the free energy corrections described in the methods section, and the CatMap steady state solver [19]. The reaction mechanism is shown in Eqs. (1)-(9).
$\mathrm{N}_{2}(\mathrm{~g})+* \leftrightarrow{ }^{*} \mathrm{~N}_{2}$

$\mathrm{H}_{2}(\mathrm{~g})+2 *_{\mathrm{h}} \leftrightarrow 2 \mathrm{H}^{* \mathrm{~h}}$

${ }^{*} \mathrm{~N}_{2}+* \leftrightarrow{ }^{*} \mathrm{~N}-\mathrm{N}+* \rightarrow 2 * \mathrm{~N}$

${ }^{*} \mathrm{~N}+\mathrm{H}^{* \mathrm{~h}} \leftrightarrow{ }^{*} \mathrm{~N}-\mathrm{H}+*_{\mathrm{h}} \rightarrow{ }^{*} \mathrm{NH}+*_{\mathrm{h}}$

${ }^{*} \mathrm{NH}+\mathrm{H}^{* \mathrm{~h}} \leftrightarrow{ }^{*} \mathrm{NH}-\mathrm{H}+*_{\mathrm{h}} \rightarrow{ }^{*} \mathrm{NH}_{2}+*_{\mathrm{h}}$

${ }^{*} \mathrm{NH}_{2}+\mathrm{H}^{* \mathrm{~h}} \leftrightarrow{ }^{*} \mathrm{NH}_{2}-\mathrm{H}+*_{\mathrm{h}} \rightarrow{ }^{*} \mathrm{NH}_{3}+*_{\mathrm{h}}$ 


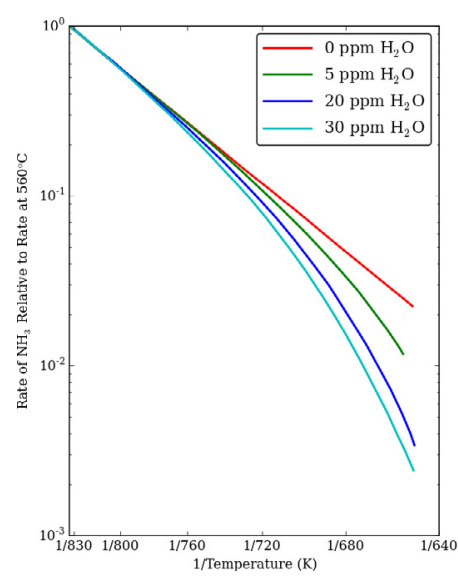

(a) Experiment

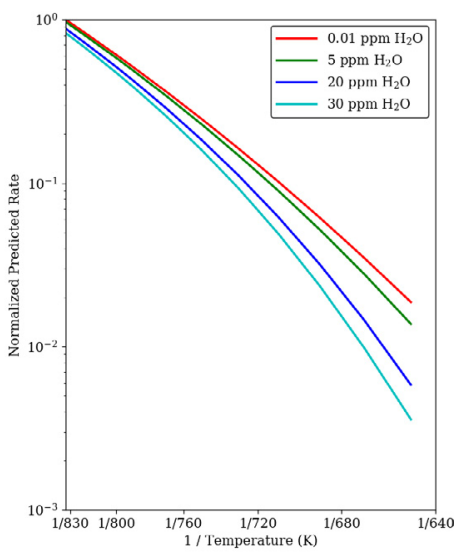

(b) Theory

Fig. 5. Log of reaction rate (turnovers per site per second) as a function of inverse temperature (1/K) according to (a) experiment [5], and (b) the theoretical model presented in this work. The catalyst used in the referenced experiment was BASF S 6-10, which is an iron catalyst with alumina "structural promoter" (used to increase surface area and prevent sintering) and a potassium electronic promoter (added to increase the intrinsic activity of the active site). The surface composition of this catalyst is shown by XPS to be mostly oxygen, aluminum, potassium, and iron. [21] In the theoretical calculations, the mole ratio of $\mathrm{N} 2: \mathrm{H} 2$ is $3: 1$, and the fraction of ammonia is $0.1 \%$. At each point, the total pressure is set to the pressure that makes the overall reaction free energy approximately that of industrial conditions $(\Delta \mathrm{G}=-0.3 \mathrm{eV})$. This was done because we are not presently interested in showing the effect of driving force on rate. The binding energies of the nitrogen intermediates are the values calculated on the K-promoted BCC iron

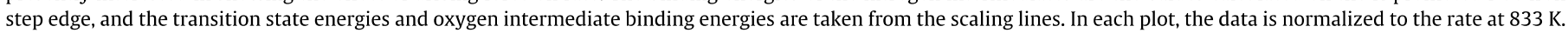
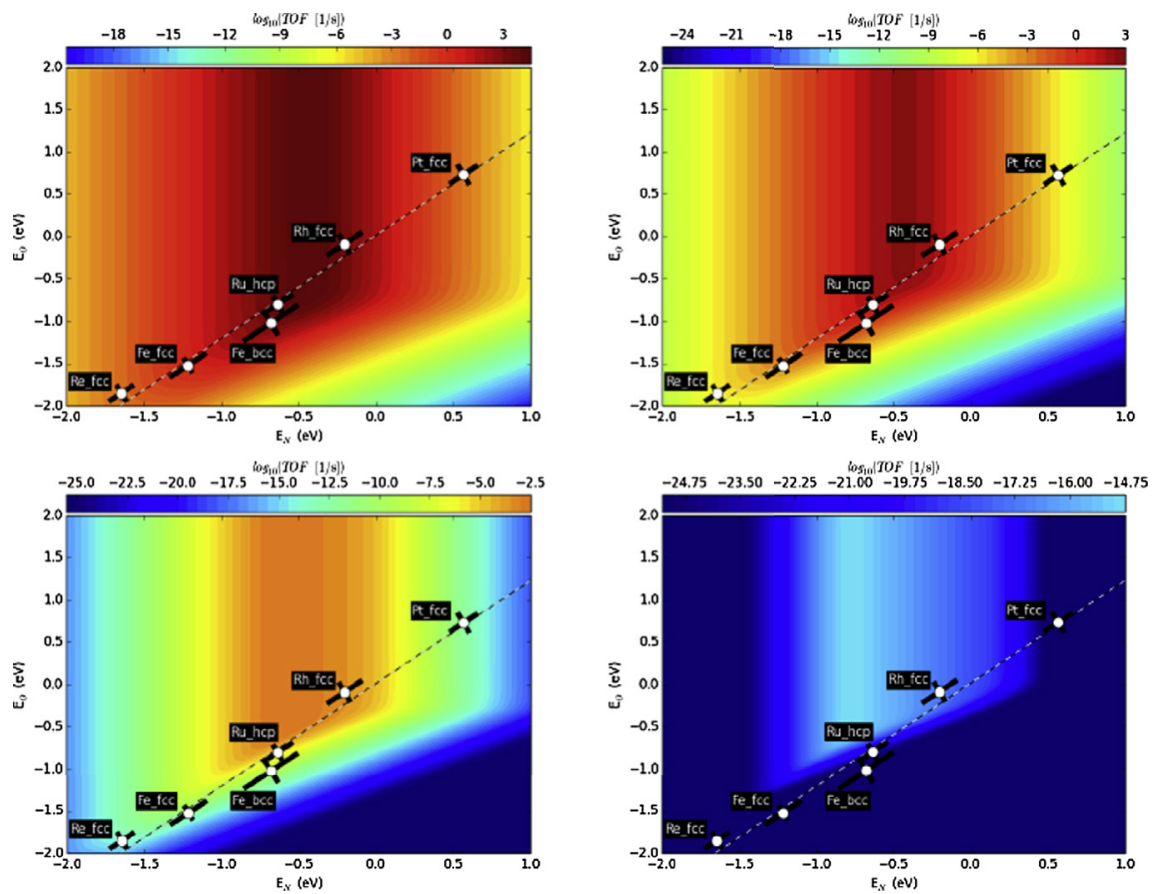

Fig. 6. Heat maps of the ammonia production rate at $900,700,500$, and $300 \mathrm{~K}$. All four simulations have 20 ppm water, $1 \%$ ammonia, and the pressure is changed to keep the $\Delta \mathrm{G}$ of the overall reaction constant. The error bars represent one standard deviation in uncertainty according to the BEEF ensemble method of uncertainty estimation [7].

${ }^{*} \mathrm{NH}_{3} \leftrightarrow \mathrm{NH}_{3}(\mathrm{~g})+*$

$\mathrm{H}_{2} \mathrm{O}(\mathrm{g})+* \leftrightarrow{ }^{*} \mathrm{O}+\mathrm{H}_{2}(\mathrm{~g})$

$2 \mathrm{H}_{2} \mathrm{O}(\mathrm{g})+2 * \leftrightarrow 2 * \mathrm{OH}+\mathrm{H}_{2}(\mathrm{~g})$

Eqs. (1)-(7) describe the dissociative ammonia synthesis pathway. Eqs. (7)-(9) allow for ${ }^{*} \mathrm{O}$ and ${ }^{*} \mathrm{OH}$ to poison the active site. These reactions are assumed to be in equilibrium because the barrier for water dissociation is known to be much lower than that of nitrogen dissociation [20]. The steady state model was solved many times at a variety of temperatures and water partial pressures, and the results are shown in Fig. 5.

There is good agreement between theory and experiment. Both theory and experiment show an apparent activation energy in the absence of water of roughly $100 \mathrm{~kJ} / \mathrm{mol}$, which is in the middle of the range of what has been previously reported [22]. Both theory and experiment show that, in the presence of even a small amount of water vapor, the reaction rate decreases with temperature much more quickly than explained by the arrhenius equation based on the high-temperature data. For example, the presence of $30 \mathrm{ppm}$ water, dropping the temperature from $550 \mathrm{C}$ to $380 \mathrm{C}$ results in a 
decrease in rate of about 3 orders of magnitude. The chief reason that increasing temperature reduces the oxygen coverage is simply entropy. ${ }^{*} \mathrm{O}$ is in equilibrium with water vapor and hydrogen gas, and since the ${ }^{*} \mathrm{~N}$ surface species occurs after the rate determining step in the reaction mechanism [23], ${ }^{*} \mathrm{~N}$ is in quasi-equilibrium with ammonia gas and hydrogen gas. ${ }^{*} \mathrm{O}$ reacting with hydrogen gas to form water vapor has a higher change in entropy than ${ }^{*} \mathrm{~N}$ reacting with hydrogen gas to form ammonia gas. Therefore, at high temperatures, it becomes more and more favorable for ${ }^{*} \mathrm{O}$ to leave the surface compared to ${ }^{*} \mathrm{~N}$. Other qualitative details, like the convergence of the rates at high temperature regardless of water content are also captured by the model. This agreement between theory and experiment indicates that the scaling lines used in the model capture the physical effects relevant to the oxygen poisoning phenomenon.

These same scaling lines were used to calculate the rate of ammonia production as a function of the catalyst's oxygen binding energy and nitrogen binding energy, shown in Fig. 6.

These heat maps provide a much more complete picture of the oxygen poisoning phenomenon. Loosely speaking, the $x$-axis can be read as 'catalyst,' and the y-axis can be read as 'water concentration.' If a catalyst falls in a region with vertical contour lines, it is unaffected by oxygen poisoning; changing the water concentration would not affect the activity of that catalyst. At $900 \mathrm{~K}$, at all points along the scaling line, the contour lines of the heat map are vertical. This shows that, at high temperature, all catalysts are not affected by oxygen poisoning. However, at $300 \mathrm{~K}$, almost the entire line falls below this region of vertical contour lines, and the rate is nearly zero for all catalysts. This shows that all industrially relevant catalysts are badly poisoned by oxygen at room temperature and $20 \mathrm{ppm}$ water vapor. The strong binding catalysts (left half of the line) become inactive due to oxygen poisoning at a higher temperature than the weak-binding catalysts (the right half of the line). At intermediate temperatures (near $500 \mathrm{~K}$ ), catalysts that are normally considered to be weaker-binding than ideal become the best catalysts if $20 \mathrm{ppm}$ water vapor is present. This may help explain why some researchers have been able to measure small amounts of ammonia production at low temperature using extreme oxygen guards or weak-binding catalysts. For example, in work done by Wang et al. [24], a detectable amount of ammonia was measured using a variety of transition metal catalysts in the presence of lithium. In the experiments, the input gases were passed through a sodium powder oxygen guard. We suggest that the use of this extreme oxygen guard was crucial to the results presented in their work. Separately, Aika reports producing measurable amounts of ammonia $\left(0.23 \mathrm{~cm}^{3} \mathrm{NH}_{3} /\right.$ (g-catalyst)/day) at 31 degrees $C$ on a potassium promoted ruthenium catalyst [25], which is weaker-binding than the industrially-used potassium promoted iron catalyst. We suggest that the use of a weak-binding catalyst contributed to the success of this experiment.

\section{Conclusions}

This study proposes a structure of the active site for industrial Haber-Bosch catalysts that has not been previously identified. We have created a DFT-based model of that active site that cap- tures the effect of oxygen poisoning on industrial Haber-Bosch catalysts and agrees with experiments. This model suggests that, as researchers work toward a low temperature thermal ammonia synthesis process, mitigating the effect of oxygen poisoning will be an important design requirement. According to our model, this could be accomplished by using an extreme oxygen guard or selecting a weaker-binding catalyst.

\section{Acknowledgements}

The authors acknowledge support from the U.S. Department of Energy Office of Basic Energy Sciences to the SUNCAT Center for Interface Science and Catalysis. Support from the Villum Foundation to the Villum Center for the Science of Sustainable Fuels and Chemicals is gratefully acknowledged. B.A.R. was supported by the NSF GFRP, Grant No. DGE-1656518.

\section{References}

[1] R. Lan, J.T.S. Irvine, S. Tao, Sci. Rep. 3 (2013) 1145.

[2] R. Schlögl, in: G. Ertl, H. Knözinger, F. Schüth, J. Weitkamp (Eds.), Handbook of Heterogeneous Catalysis, Wiley-VCH, 2008.

[3] K. Teller, New Methanol and Fertilizer Plants to Increase Already-growing Industrial Natural Gas Use, United States Energy Information Administration, 2015.

[4] D.E. Garrett, Chemical Engineering Economics, Springer, Netherlands, 1989, pp. 258.

[5] M. Appl, Ammonia, 2. Production Processes. Ullmann's Encyclopedia of Industrial Chemistry, Wiley, 2002, pp. 167-169.

[6] S.R. Bahn, K.W. Jacobsen, Comput. Sci. Eng. 4 (2002) 56-66.

[7] J. Wellendorff, K.T. Lundgaard, A. Møgelhøj, V. Petzold, D.D. Landis, J.K. Nørskov, T. Bligaard, K.W. Jacobsen, Phys. Rev. B 85 (2012) 1-23.

[8] H.J. Monkhorst, J.D. Pack, Phys. Rev. B 13 (1976) 5188-5192.

[9] A. Alavi, P. Hu, T. Deutsch, P.L. Silvestrelli, J. Hutter, Phys. Rev. Lett. 80 (1998) 3650-3653.

[10] Z.-P. Liu, P.J. Hu, Am. Chem. Soc. 125 (2003) 1958-1967.

[11] L. Yu, F. Abild-Pedersen, ACS Catal. 7 (2016) 864-871.

[12] R. Brogaard, R. Henry, Y.J. Schuurman, A. Medford, P. Moses, P. Beato, S.K. Svelle, J. Nÿrskov, U. Olsbye, J. Catal. 314 (2014) 159-169.

[13] J. Jennings, Catalytic Ammonia Synthesis, Springer Science and Business Media, LLC, 1991, pp. 141-143.

[14] G. Henkelman, A. Arnaldsson, H. Jónsson, Comput. Mater. Sci. 36 (2006) 354360.

[15] F. Calle-Vallejo, D. Loffreda, M.T.M. Koper, P. Sautet, Nat. Chem. 7 (2015) 403.

[16] A. Vojvodic, A.J. Medford, F. Studt, F. Abild-Pedersen, T.S. Khan, T. Bligaard, J.K. Nørskov, Chem. Phys. Lett. 598 (2014) 108-112.

[17] P. Crawford, P. Hu, J. Phys. Chem. B 110 (2006) 24929-24935, PMID: 17149914.

[18] B. Fastrup, H. Nygård Nielsen, Catal. Lett. 14 (1992) 233-239.

[19] A.J. Medford, C. Shi, M.J. Hoffmann, A.C. Lausche, S.R. Fitzgibbon, T. Bligaard, J. K. Nørskov, Catal. Lett. 145 (2015) 794-807.

[20] A. Michaelides, Z.-P. Liu, C.J. Zhang, A. Alavi, D.A. King, P. Hu, J. Am. Chem. Soc. 125 (2003) 3704-3705, PMID: 12656593.

[21] J.R. Anderson, M. Boudart, in: J.R. Anderson, M. Boudart (Eds.), Catalysis: Science and Technology, Springer-Verlag, 1983, p. 258.

[22] A. Nielsen, Ammonia: Catalysis and Manufacture, Springer, 1995, pp. 83.

[23] R. Schlögl, Angew. Chem. Int. Ed. 42 (2003) 2004-2008.

[24] P. Wang, F. Chang, W. Gao, J. Guo, G. Wu, T. He, P. Chen, Nat. Chem. 9 (2016) 64.

[25] K.-I. Aika, VCH Verlagsgesellschaft (1986) 558-559. 